\title{
Acquired Properties Comparison of Solid Nitriding, Gas Nitriding and Plasma Nitriding in Tool Steels
}

\author{
Elisangela Aparecida dos Santos de Almeida ${ }^{a *}$, Júlio César Giubilei Milan ${ }^{a}$, César Edil da Costa ${ }^{a}$
}

\author{
${ }^{a}$ Santa Catarina State University - UDESC, Joinville, SC, Brazil
}

Received: December 3, 2013; Revised: January 15, 2015

\begin{abstract}
Plasma nitriding, gas nitriding and solid nitriding were applied in tool steels (AISI H13, AISI P20 and N-8550). The acquired properties were compared and evaluated on these three processes with the aim to verify the solid nitriding performance. In order to promote the solid nitriding, the samples were surrounded by a solid compound with the $\mathrm{Fe}_{4} \mathrm{KCN}$ stoichiometric formula, inside an aluminum recipient. All thermochemical nitriding processes were performed at $560{ }^{\circ} \mathrm{C}$. The wear behavior has been assessed by dry sliding wear test, using a pin-on-disk apparatus, the amount of wear was obtained by the use of a profilometer. The wear tracks were analyzed using SEM (Scanning Electron Microscopy). After the wear test the samples were transversally cut, to obtain the Vickers microhardness. Solid nitriding presented good performance, formation of a nitriding layer, values of microhardness compatible with the other processes and the best results of wear.
\end{abstract}

Keywords: solid nitriding, sliding wear, tool steels, wear behavior

\section{Introduction}

The tool life is mainly determined by the surface of the materials, it is important that the surface has properties like: corrosion resistance, wear resistance and oxidation resistance ${ }^{1}$.

In order to improve surface properties some surface treatments are applied, but there is a high cost involved. It can be stated that the development and analysis of new techniques for surface treatment which involves lower costs are very important.

Some coatings are used with the aim to protect the surface or improve material's performance. The diffusion coatings consist in the diffusion of a metal or nonmetal into the material substrate at high temperatures. This treatment results not only in modification of the surface chemical composition but also new phases can be formed on the substrate ${ }^{2}$.

Nitriding is a thermochemical treatment that diffuses atomic nitrogen in the steel substrate. This treatment provides not only greater surface hardness to the steel but also abrasion, fatigue and corrosion resistance are increased, combined with good toughness and plasticity ${ }^{3}$.

The absence of oxides and contaminants is very important to the diffusion of nitrogen into the substrate ${ }^{4-6}$.

With the nitriding treatment we produce different layers on the steel, the compound layer also called white layer, and the diffusion layer. Through the control of plasma process parameters that is possible to avoid the formation of the white layer, or produce a single layer of $\mathrm{Fe}_{4} \mathrm{~N}-\gamma^{\prime}$ or $\mathrm{Fe}_{3} \mathrm{~N}-\varepsilon^{[7-10]}$.

The white layer is a mixture of iron nitrides $\left(\mathrm{Fe}_{4} \mathrm{~N}-\gamma\right.$ ' and $\mathrm{Fe}_{3} \mathrm{~N}-\varepsilon$ ), and the diffusion zone is a solid solution zone that is rich in nitrogen, with some precipitates ${ }^{11}$.

*e-mail: elisangela_s_almeida@yahoo.com.br
The influence of nitriding treatment on the wear performance and on the microstructure of steel has been extensively studied.

It is has been observed that an increase on the nitriding time and consequently an increase on the thickness of nitrided layer lead to an increase of the forging die durability $^{12}$. It is also stated that nitriding effects on the wear resistance are greater than carburizing ${ }^{13}$.

Plasma nitriding treatment can reduce the wear loss of the treated samples that were submitted to unlubricated pinon-disk test. It is also observed that an increase on the surface hardness improves the wear resistance. The amount of $\mathrm{Fe}_{3} \mathrm{~N}-\varepsilon$ also affects the wear rate; the greatest it is the lowest is the wear rate. It is due to the reduced sliding system of the hcp crystalline structure of the $\mathrm{Fe}_{3} \mathrm{~N}-\varepsilon$. However when a thin compound layer is produced it can be broken during sliding as result, particles are detached from the layer becoming abrasive particles, consequently the wear rate increases ${ }^{14}$.

Comparing the mechanisms of wear on treated and untreated samples in field, one can observe that there is a reduction of adhesion on treated samples. And it is stated that this mechanism reduction helps increasing the life time of the tool ${ }^{15}$.

Plasma nitriding treatment produces a layer that can increase the hardness of the material about 5 times. It is due to the formation of a fine dispersion of nitride particles $\left(\mathrm{CrN}, \mathrm{Fe}_{4} \mathrm{~N}\right.$ and $\left.\mathrm{Fe}_{3} \mathrm{~N}\right)$. This hard and fine grain structure also helps to eliminate the adhesion effect of the dry sliding test ${ }^{16}$.

Studying the influences of plasma nitriding on samples of quenched and tempered DIN 1.2210 cold work tool steel, it was possible to identify the formation of the phases $\mathrm{Fe}_{4} \mathrm{~N}$ and $\mathrm{Fe}_{3} \mathrm{~N}$ on the surface of all specimens. Increasing the treatment temperature results in an increase in the amount of $\mathrm{Fe}_{4} \mathrm{~N}-\gamma$ ' and the amount of $\mathrm{Fe}_{3} \mathrm{~N}-\varepsilon$ decreases. And increasing 
the treatment time results in an increment of both amounts. Temperature and time affect the hardness of the specimen, if these parameters are increased there is an increment in the surface hardness. Specimens that present higher surface hardness, $\mathrm{Fe}_{3} \mathrm{~N}-\varepsilon$ formation and thicker compound (white) layer perform better wear and corrosion resistance ${ }^{17}$.

The solid nitriding consists in provide the diffusion of nitrogen into the steel using a solid granulated $\left(\mathrm{Fe}_{4} \mathrm{KCN}\right)$. The samples are surrounded by this compound and confined inside an aluminum bowl. This pack is introduced in a muffle oven and the temperature is set to $560{ }^{\circ} \mathrm{C}$.

The aim of this study is the analysis of solid nitriding that is a technique not well diffused of treatment, in comparison with the processes of gas and plasma nitriding in tool steels, considering the wear behavior before and after the thermochemical treatments.

In order to evaluate the properties after the thermochemical treatments, a comparison of the solid, gas and plasma nitriding acquired properties was carried out. The volume of removed material and the coefficient of friction were obtained through unlubricated pin-on-disk sliding wear test. The wear track was analyzed by scanning electron microscopy. Microhardness tests were applied to the layers and the hardness profile of the samples were evaluated.

\section{Materials and Methods}

\subsection{Materials}

AISI H13, AISI P20 and N-8550. These tool steels were chosen due to the large application of these on tools production. Materials' composition is shown in Table 1.

The granulated used to the solid nitriding is commercially known as Turbonit $\mathrm{k}-20^{\circledR}$. Its stoichiometric formula is $\mathrm{Fe}_{4} \mathrm{KCN}$, as the manufacturer informed.

The equipments used were: Optic Microscope, Scan Electron Microscope (SEM), Microhardness equipment, X-Ray Diffractometer, Muffle Oven to promote the solid nitriding treatment, Tribometer (pin-on-disk), Profilometer.

\subsection{Samples preparation}

AISI H13, AISI P20 and N-8550 substrate samples, measuring $\varnothing 1$ inch x $15 \mathrm{~mm}$, were obtained from commercial bars. The samples were polished with abrasive particles up to $1 \mu \mathrm{m}$ and submitted to the thermochemical treatments as obtained from the manufacturer. The N-8550 is provided quenched and tempered, the AISI H13 is provided annealed and the AISI P20 is provided quenched and tempered. Prior to the treatments the samples were degreased.

\subsection{Nitriding treatments}

Gas, plasma and solid nitriding were applied to the samples. The temperature for the three thermochemical treatments was $560{ }^{\circ} \mathrm{C}$. Gas nitriding atmosphere was $50 \%$
$\mathrm{NH}_{3}, 50 \% \mathrm{~N}_{2}$, and $\mathrm{CO}_{2}$ in a small amount, for 10 hours. Plasma nitriding atmosphere was $20 \% \mathrm{~N}_{2}$ and $80 \% \mathrm{H}_{2}$, 3 hours treatment. The solid nitriding was applied for 3 hours and 10 hours treatment.

The solid nitriding uses a solid granulated $\left(\mathrm{Fe}_{4} \mathrm{KCN}\right)$ called by the manufacturer Turbonit $\mathrm{k}-20^{\circledR}$. The samples were surrounded by the granulated inside an aluminum made bowl and confined inside it, so that the gas generated is kept inside the bowl. The distance between the samples was about $15 \mathrm{~mm}$, and also $15 \mathrm{~mm}$ to the edge of the recipient. This method uses a muffle oven to promote the heating for the nitriding process.

In this process, the heating of the granulated generates atomic nitrogen that in contact with the surface of the samples enables the introduction of this element on the surface. Actually the solid nitriding occurs through a gas nitriding process.

\subsection{Microscopy and microhardness}

SEM was used to observe the wear mechanisms and the cross section of the samples.

The microhardness profiles of the layers were determined using Vickers microhardness indentation test. Three indentations were done for each depth with a load of $10 \mathrm{gf}\left(\mathrm{HV}_{0,01}\right)$, and the result was the average of the microhardness values.

\subsection{Wear test}

Pin-on-disk equipment was used to evaluate the effects of the different kinds of nitriding methods on tribological properties. The samples were submitted to the unlubricated sliding test according to ASTM G99/95 reapproved $2000^{18}$.

Prior to the wear test, the samples were submitted to ultrasonic cleaning, in order to remove solid particles that could interfere on the results.

This test was performed on a homemade Tribometer. Friction coefficient was monitored through the measurement of the friction force during the wear test. Six tests were performed for each condition, and the wear tests were conducted both on the top and bottom of the samples.

The counter-bodies were polished alumina spheres with $6 \mathrm{~mm}$ diameter. The Alumina $\left(\mathrm{Al}_{2} \mathrm{O}_{3}\right)$ Vickers hardness is about 1500 to $1650 \mathrm{kgf} / \mathrm{mm}^{2}$. The tests were performed on the conditions bellow:

- Temperature: About $25^{\circ} \mathrm{C}$;

- Relative Humidity: Maintained at $30 \%$ or less;

- Applied Load on pin: 10N;

- Sliding Speed: 0,1 m/s;

- Sliding Distance: 1000 m;

- Wear Track Radius: $6 \mathrm{~mm}$.

The wear volume was obtained by the volume loss, quantified through the track profile that was measured with

Table 1. Materials Composition (\% weight).

\begin{tabular}{|c|c|c|c|c|c|c|c|c|c|c|}
\hline & $\mathrm{Cr}$ & Si & Мo & $\mathrm{C}$ & Mn & $\mathbf{V}$ & $\mathbf{N i}$ & Al & $\mathbf{P}$ & $\mathbf{W}$ \\
\hline AISI H13 & 5.2 & 0.89 & 1.25 & 0.39 & 0.31 & 0.82 & 0.17 & 0.018 & 0.025 & 0.06 \\
\hline AISI P20 & 1.86 & 0.28 & 0.42 & 0.35 & 0.02 & 0.01 & 0.87 & $\ldots .$. & 0.02 & $\ldots .$. \\
\hline N-8550 & 1.65 & 0.2 & 0.23 & 0.33 & 0.50 & $\ldots \ldots$ & 0.96 & 0.98 & $\ldots \ldots$ & $\ldots$. \\
\hline
\end{tabular}


a profilometer, on which 6 evaluations of the track profile were performed in each face of the sample.

The results obtained on this measurement were processed with a computer routine, which calculates the volume loss through the area of the worn track.

\section{Results and Discussion}

The Vickers Hardness $\left(\mathrm{HV}_{1}\right)$ of the tool steels are presented on Figure 1. These results represent the bulk hardness of the materials and were obtained from the surface of each specimen. The samples were submitted to the test without thermochemical treatment (nitriding).

Figure 2 shows the structural zones produced by the nitriding treatment. The first layer observed in all cases is the white layer or compound layer, this layer consistes in iron nitrides on the surface of the case. The second layer produced by the diffusion of nitrogen bellow the compound layer is named diffusion layer. The thicker white layer was produced by the solid nitriding treatment on the AISI H13 samples.

The microhardness profiles of AISI H13 samples nitrided by three different processes are shown on Figure 3. The microhardness profiles show the hardening of AISI H13 due to the introduction of atomic nitrogen in its structure. In the thermochemical treatment of plasma and solid nitriding (10h), the hardness achieved approximately $723 \mathrm{HV}$, the gas nitriding treatment hardness was higher, reaching approximately $828 \mathrm{HV}$. The measurements were made at a certain distance from the surface to avoid the effect that the edge might have on the result.

The thickness of the nitrided layers formed to the AISI H13 solid nitrided reached aproximately $47 \mu \mathrm{m}$, that explains the curve behavior. The plasma nitrided layers reached aproximately $100 \mu \mathrm{m}$, then the hardness curve decline to the bulk hardness of the material.

Figures 4 and 5 show the hardening profile of AISI P20 and N-8550. These profiles show the hardening of the steel through the introduction of nitrogen in the structure.

The microhardness profile to the AISI P20 shows that the higher values of hardness were obtained through gas and plasma nitriding. For the N-8550 gas and solid nitriding process generated the higher values of microhardness.
Figure 6 graphically represents the coefficients of friction obtained during the wear test for the samples. These results are the average for the coefficients of friction values in steady regime.

The treated samples coefficients of friction of AISI P20 and AISI H13 did not suffer significant changes in relation to the non-treated samples.

It can be noted that the coefficient of friction did not present great changes, remaining very close in almost all situations.

The wear volumes of the three materials without thermochemical treatment are shown in Figure 7. Analyzing the materials without treatment, it is seen that AISI H13 suffered the greater removal of material, comparing with AISI P20 and N-8550. As the materials were submitted to the tests as received from the manufacturer, AISI H13 presented the lowest hardness value as shown in Figure 1. The hardness value of AISI H13 was about 39\% smaller than the AISI P20 hardness and 56\% smaller than the N-8550 hardness. Considering this, it was already expected that the wear resistance of this material was inferior under the condition of non-nitrided material.

Figure 8 shows the results of wear volume of the treated samples. Comparing figures 7 and 8, there was a reduction of the wear volume when the samples were nitrided by any of the methods (gas, plasma or solid). For AISI P20 and specially for AISI H13, the nitriding thermochemical treatments promoted a greater reduction of the material removal (material loss) by wear.

In the case of N-8550 there was also a reduction on the volume of removed material during the wear test, but, smaller than the reduction observed at AISI P20 and AISI H13.

It is noticed that the results of wear volume of the solid nitriding, not only for the treatment carried out during 10 hours but also for 3 hours, proved to be competitive related to the gas and plasma nitriding.

The wear results of the samples treated by solid nitriding during 10 hours are the best for the three materials. And also, the 3 hours solid nitrided samples presented wear volume results slightly lower than the ones obtained for the gas nitrided samples, as shown in Figure 8.

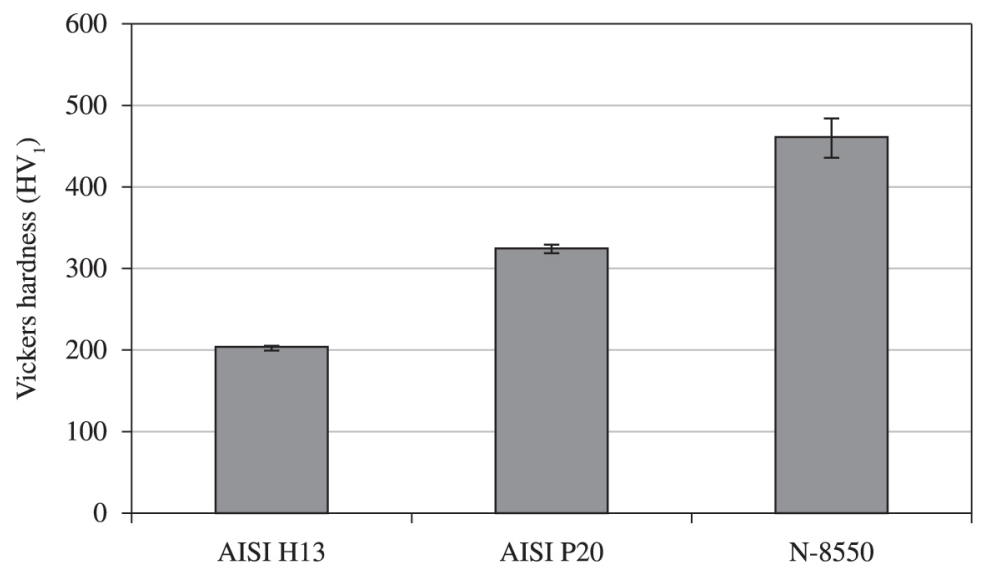

Figure 1. Vickers Hardness Values for the three materials as received from the manufacturer, without nitriding treatment. 


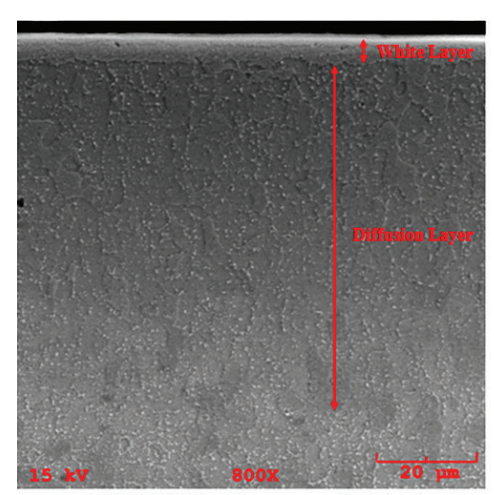

AISI H13 plasma nitrided

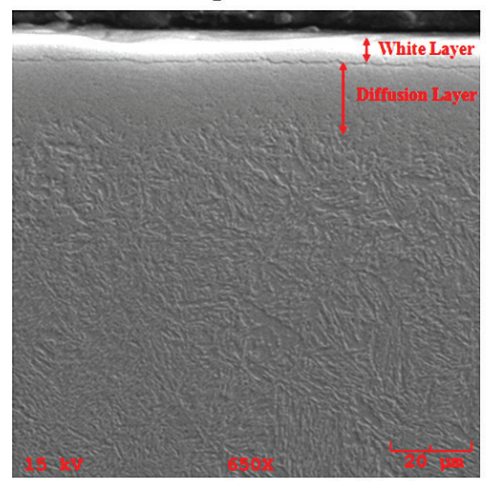

AISI P20 plasma nitrided

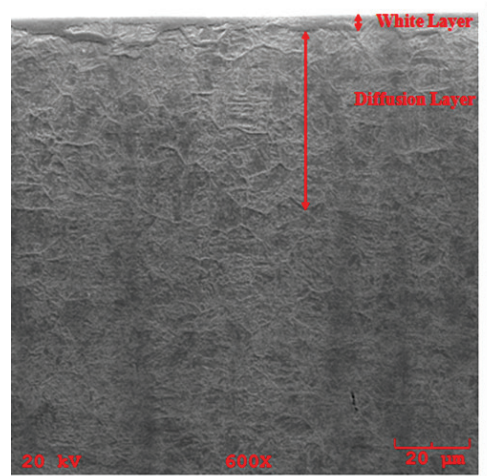

N-8550 plasma nitrided

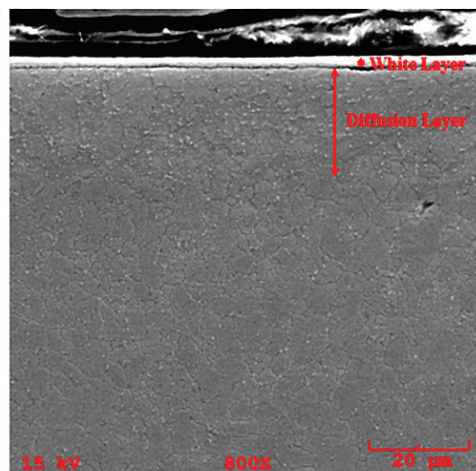

AISI H13 gas nitrided

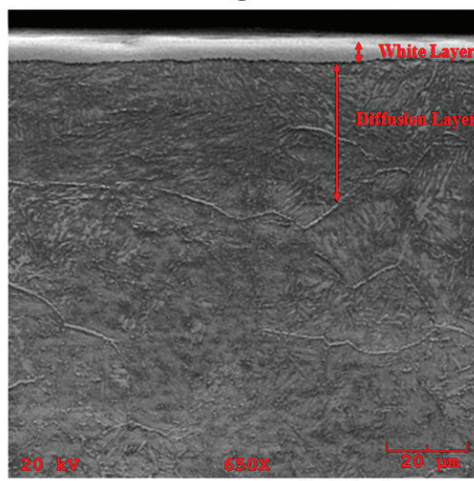

AISI P20 gas nitrided

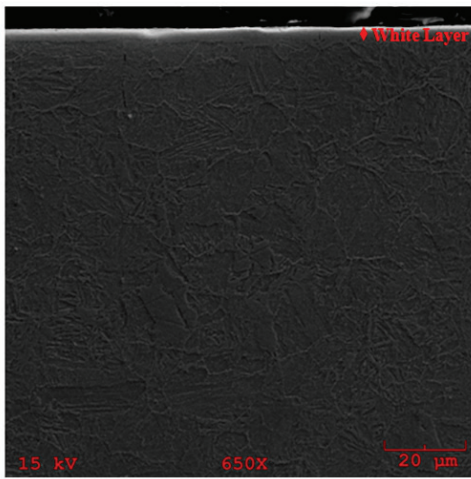

$\mathrm{N}-8550$ gas nitrided

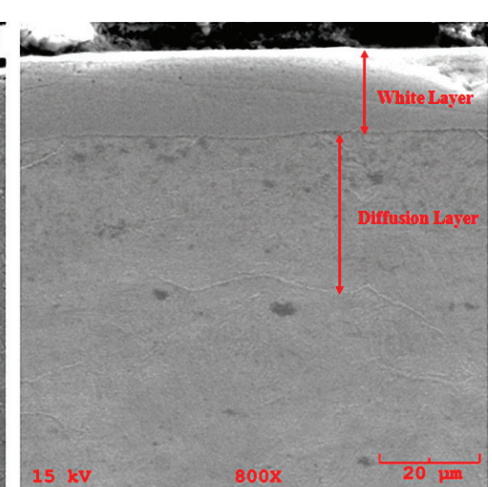

AISI H13 solid nitrided

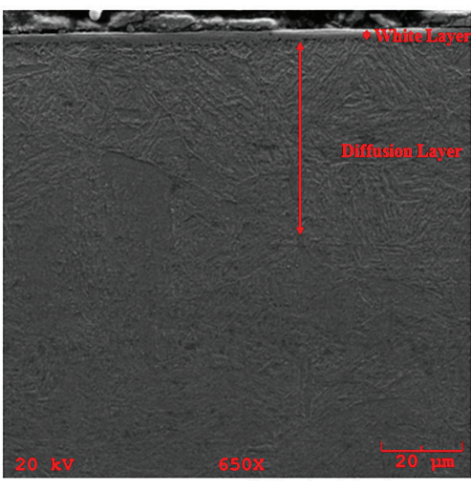

AISI P20 solid nitrided

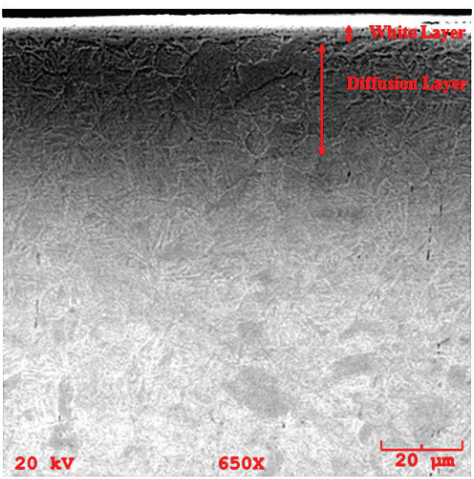

$\mathrm{N}-8550$ solid nitrided

Figure 2. SEM micrographs of AISI H13, AISI P20 and N-8550 cross section, referring to nitrided layers produced by the ntriding treatments.

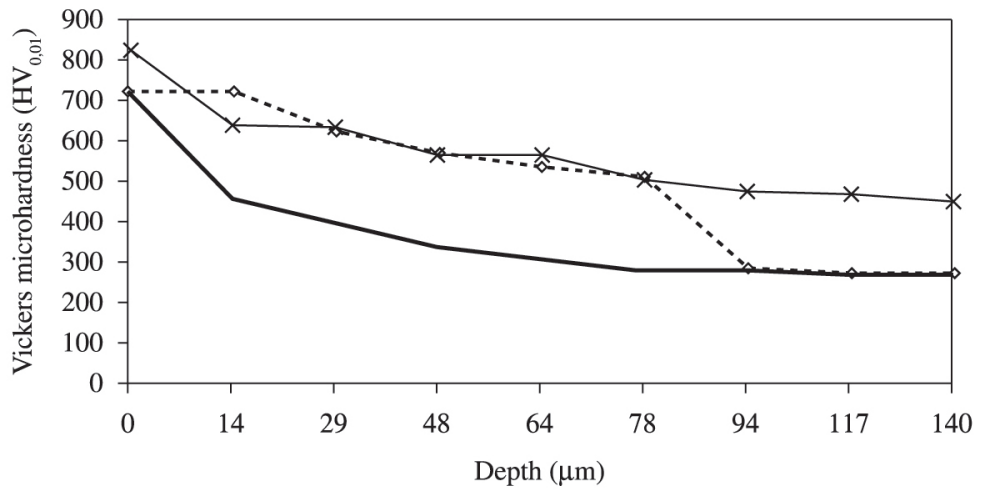

- $\diamond$ - Hardness H13 plasma $\rightarrow$ Hardness H13 gas $\longrightarrow$ Hardness H13 solid

Figure 3. Microhardness profile for samples of AISI H13, nitrided by three different processes (plasma, gas, and solid (10h)) 


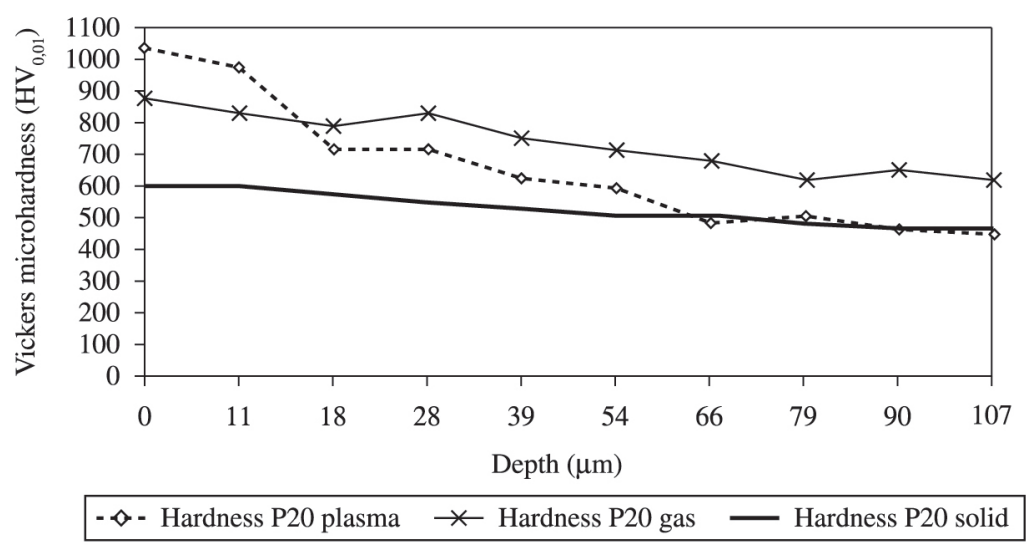

Figure 4. Microhardness profile for samples of AISI P20, nitrided by three different processes (plasma, gas, and solid (10h)).

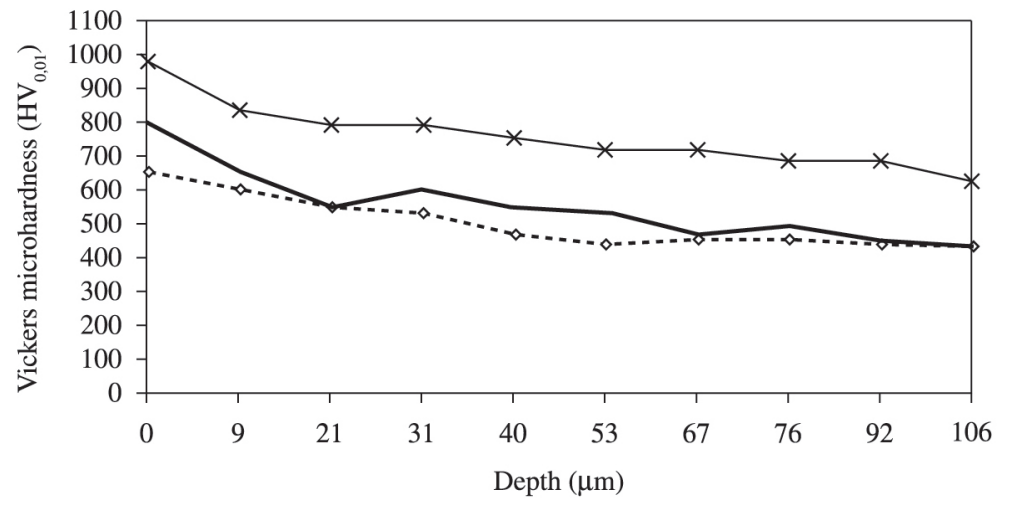

$\rightarrow$ - Hardness N8550 plasma $\rightarrow$ Hardness N8550 gas - Hardness N8550 solid

Figure 5. Microhardness profile for samples of N-8550, nitrided by three different processes (plasma, gas, and solid (10h)).

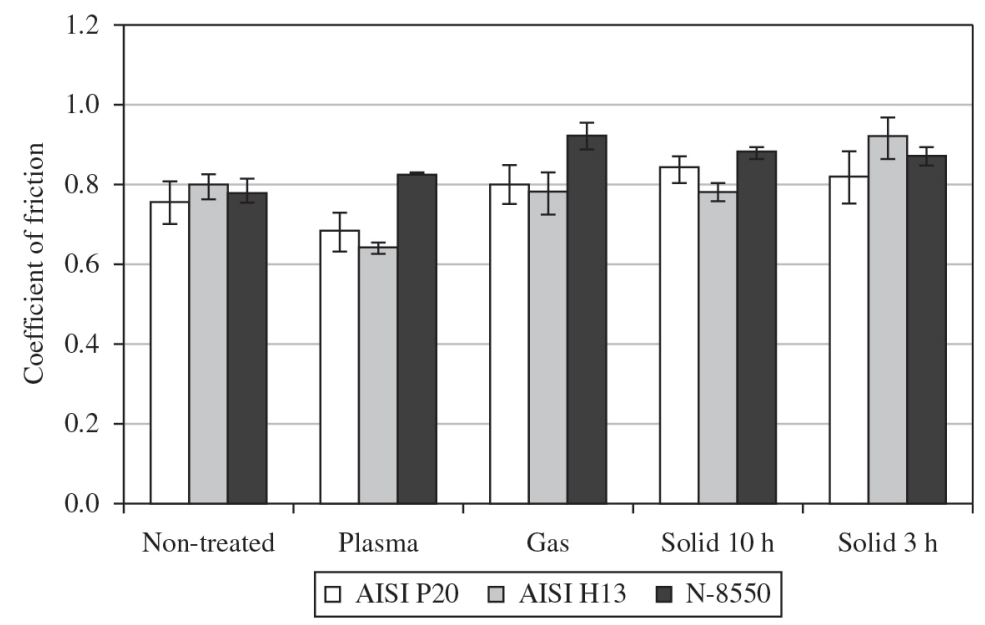

Figure 6. Coefficients of friction obtained during the wear test.

Besides, increasing the solid nitriding time results in a reduction in the volume of removed material.

The wear volume reduction is explained by the superficial introduction of nitrogen on the steel, promoting a layer with high hardness level because of the rise of iron nitrides or nitrides of alloying elements, that was observed for gas and plasma nitriding. And in the case of solid nitriding, it is also due to the formation of carbides, by the difusion of carbon atoms in the materials. As we can observe through X-ray diffractometry, Figure 9.

Although the results of wear resistance have been favorable for solid nitriding, is not possible to say that the 


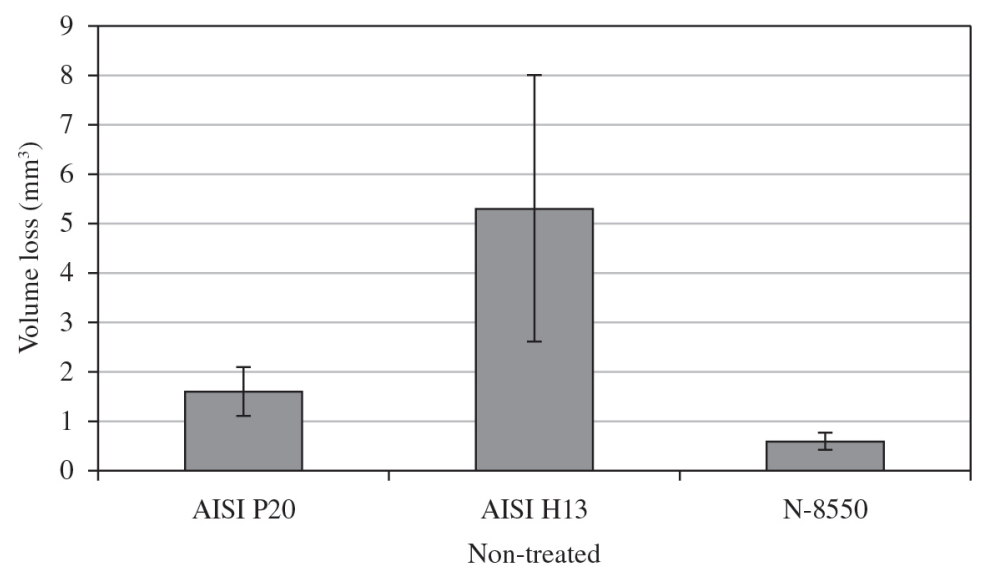

Figure 7. Wear volume results of non-treated AISI H13, AISI P20 and N-8550.

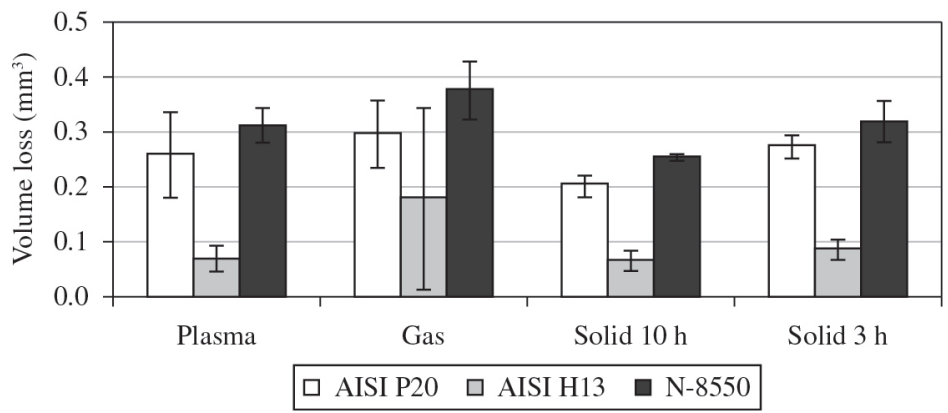

Figure 8. Wear volume results for the steels AISI P20, AISI H13 and N-8550 according to the thermochemical treatment conducted.

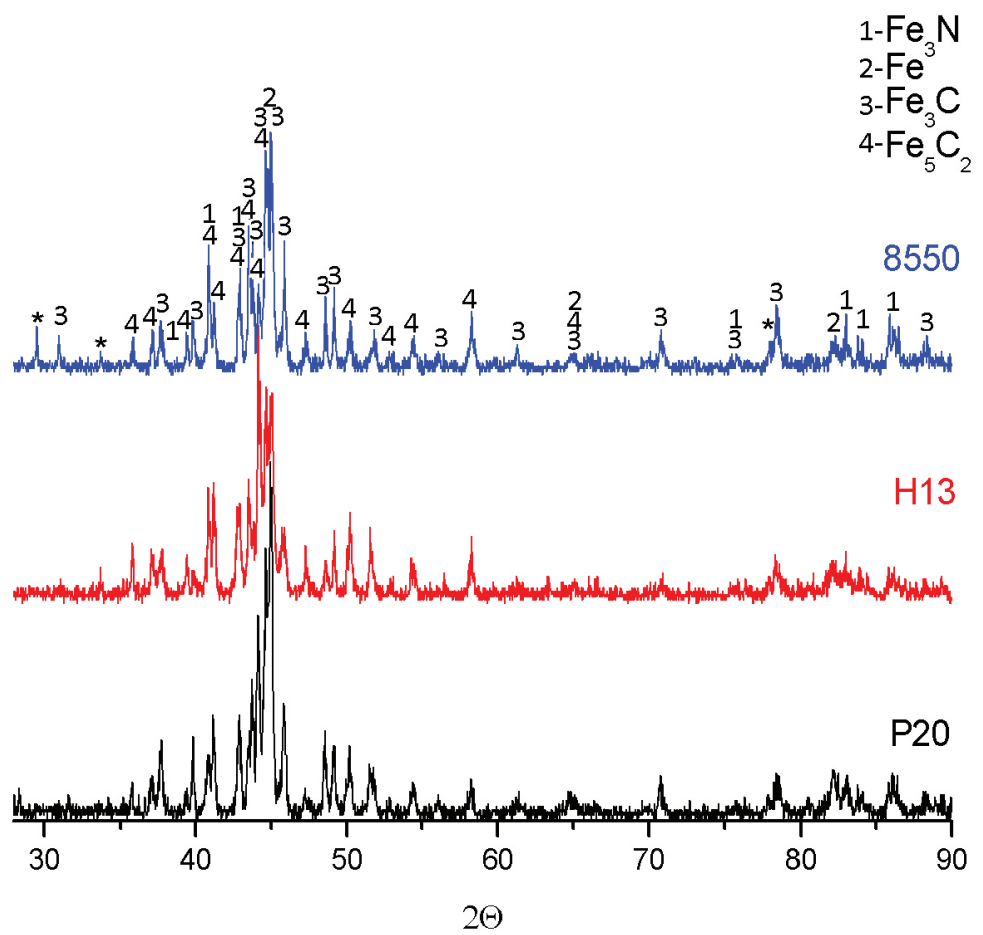

Figure 9. X-Ray diffraction obtained to the samples of solid nitriding treatment (10h). 


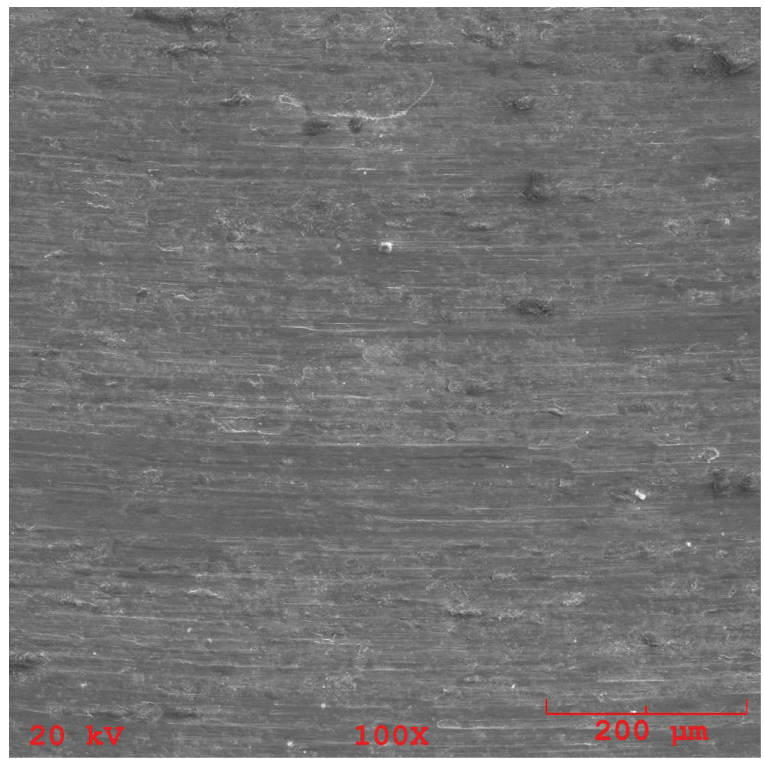

(a)

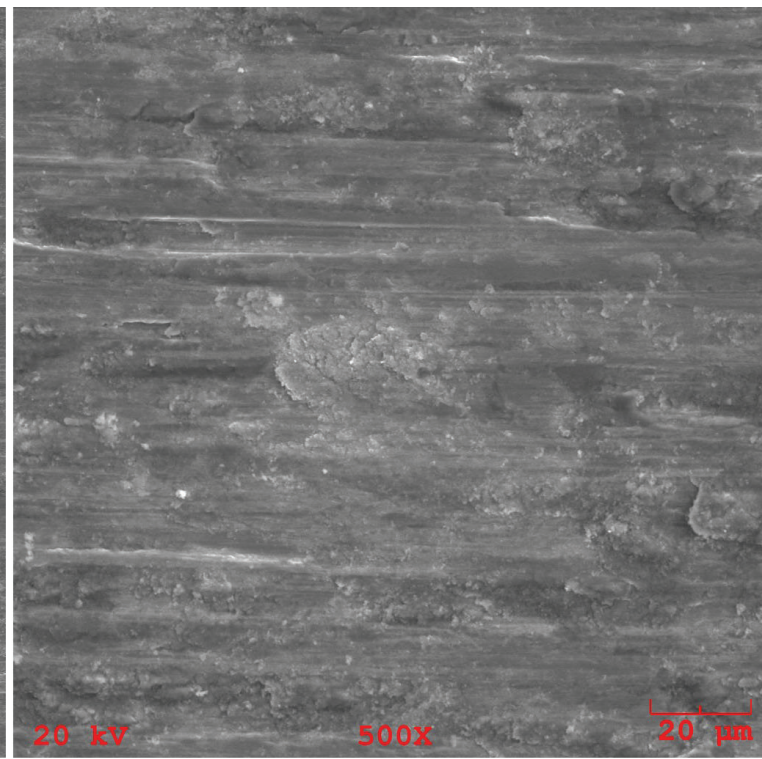

(b)

Figure 10. SEM micrographs of wear tracks referring to samples of AISI H13 without treatment: a) 100x and b) 500x.

process is competitive yet. It is necessary to evaluate the treatment in more severe conditions during the wear tests to verify the efficiency of the formed layer.

The microscopy of the tracks was performed on AISI H13 without thermochemical treatment, and also in the wear tracks of steel treated by gas nitriding, plasma and solid $10 \mathrm{~h}$.

Figure 10 presents the wear tracks for the AISI H13 without treatment. In these micrographies it is possible to observe large plastic deformation, presence of risk/grooves in the wear track parallel to the sliding direction, indicating signs of abrasive wear.

This abrasion may have been caused either by the counter-body with greater hardness, or by wear particles detached from the body (sample) that remained at the interface, suffered great deformation, increasing its resistance and also suffered oxidation. The adhesion also seems to be evidenced by Figure $10 \mathrm{~b}$ to non-nitrided AISI H13 and previously discussed by Uma Devi et al. ${ }^{15}$. In this case it is possible that there has been adhesion of the material of the specimen on the sphere and then this material is transferred from the sphere to the specimen, since the sphere composition $\left(\mathrm{Al}_{2} \mathrm{O}_{3}\right)$ has less chemical affinity with the material of the specimens, which would reduce the adhesion. Performing the wear test without the use of lubricants can promote adhesion of materials.

Figure 11 is an inner region of the track. In this micrograph, there are two points at which chemical analysis (EDS) was held.

In this image, Figure 11, it is observed that part of the surface of the track seems to be composed of smaller particles, deformed in the direction of the movement and deposited in layers overlapping one another.

Figure 12 shows the spectrum of composition for non-nitrided steel AISI H13 referring to regions 1 and 2 of Figure 11.

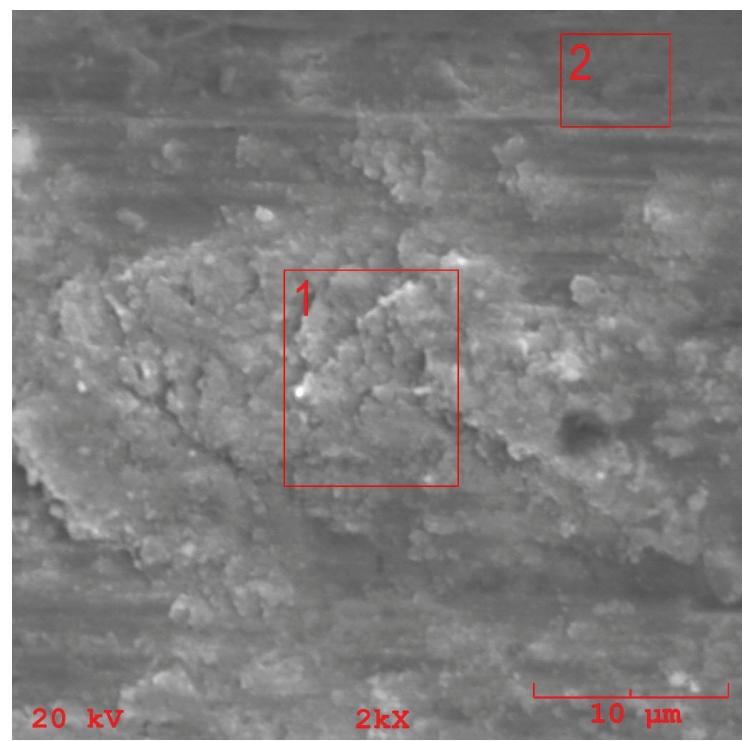

Figure 11. SEM micrograph referring to the wear track of AISI H13 sample without treatment, showing the regions analyzed by EDS.

In region 1, the presence of oxygen indicates that the material in this region suffered oxidation. There was also a small amount of aluminum. According to the manufacturer of the material, this element is not part of the composition of AISI H13 (Table 1). Thus, it is believed that there was a small transference of material from the counter-body (sphere) for the tested surface. Whereas in the second region we can also note the presence of oxygen, however, in lower amounts and the presence of aluminum. The spectra confirm that the region 1 has suffered a greater oxidation than the region 2 . 


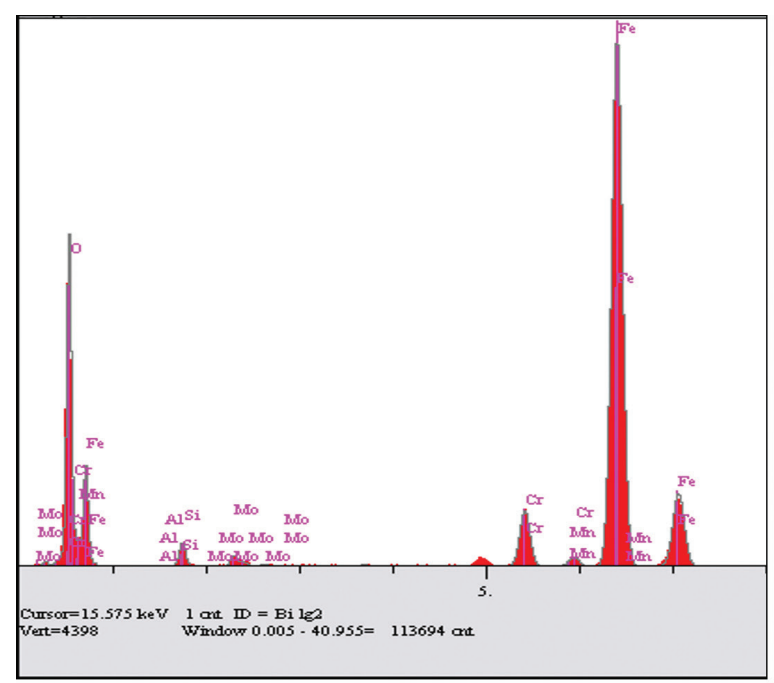

(a)

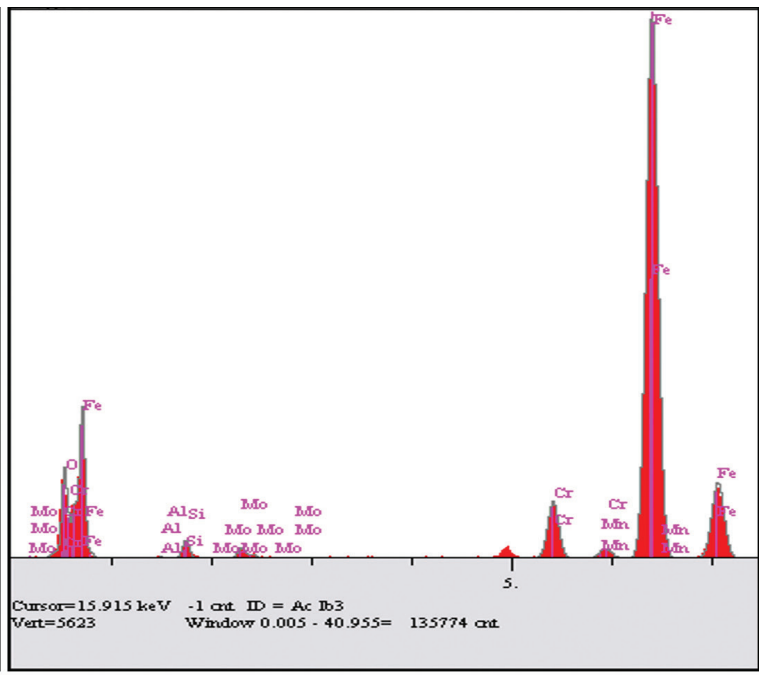

(b)

Figure 12. Spectrum of non-nitrided AISI H13 referring to the region (a) region 1 and (b) region 2.

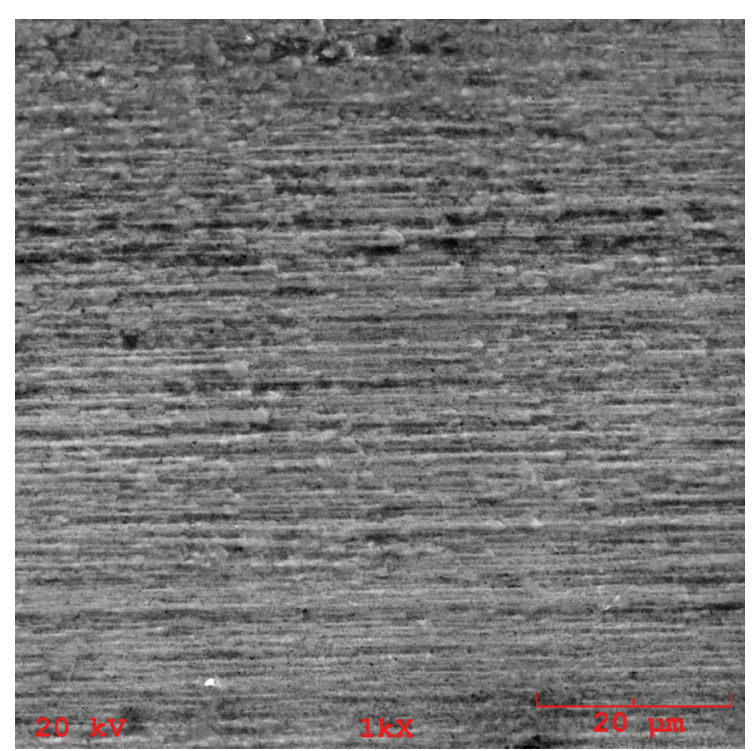

Figure 13. SEM micrograph referring to the wear track of AISI H13 sample solid nitrided $10 \mathrm{~h}$.

These spectra indicating the presence of oxides and the aspect of the worn surface, Figure 11, suggest that there was also tribo-chemical wear.

The micrograph of Figure 13, represents the AISI H13 thermochemically treated by solid nitriding 10h, the appearance of the track to the other treatments is similar. There is a reduction on the signs of adhesive wear, such as material transfer and/or material adhered on the track of the specimens.

The micrographs of the AISI H13 thermochemically treated are observed in Figure 14.

The micrographs of Figure 14 show signs of wear through the risks / grooves presented on the tracks, especially in the cases of plasma and solid nitriding treatment. This

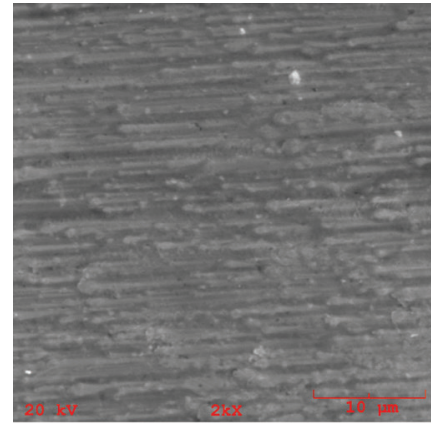

(a)

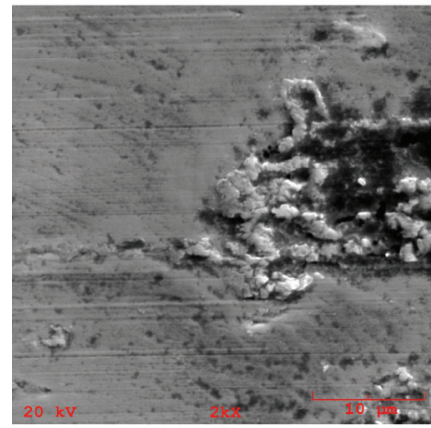

(b)

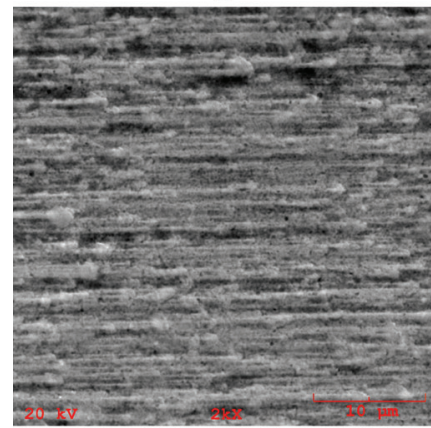

(c)

Figure 14. SEM micrographs referring to the wear tracks of AISI H13 samples: a) plasma nitrided b) gas nitrided c) solid nitrided $10 \mathrm{~h}$. 
is due to the presence of hard particles from the nitriding treatment on the contact interface between the counter-body (sphere) and the sample.

The oxidation observed in sliding wear can be explained by the fact that the metallic fragments retained in the interface may break into small pieces and oxidize rapidly due to its large exposed area. The oxidation can also be promoted by the heat generated by plastic deformation that the sample or the fragments suffer in contact with the counter-body. Then there is an agglomerate of particles and the surface oxidation occurs.

\section{Conclusions}

Based on the results it is possible to conclude that:

- The nitriding treatments promoted a higher hardness surface to all the materials, and improved the wear resistance.

- The microhardness on the superficial layer for the solid nitriding treatment reached the same values or

\section{References}

1. Petrova RS, Suwattananont N and Samardzic V. The effect of boronizing on metallic alloys for automotive applications. Journal of Materials Engineering and Performance. 2008; 17(3):340-345. http://dx.doi.org/10.1007/s11665-008-9228-2.

2. Hunger HJ and Trute G. Boronizing to produce wear-resistant surface layers. Heat Treatment of Metals. 1994; 2:31-39.

3. Fattah M and Mahboubi F. Comparison of ferritic and austenitic plasma nitriding and nitrocarburizing behavior of AISI 4140 low alloy steel. Materials \& Design. 2010; 31(8):3915-3921. http://dx.doi.org/10.1016/j.matdes.2010.03.008.

4. Figueroa CA, Wisnivesky D and Alvarez F. Effect of hidrogen and oxigen on stainless steel nitriding. Journal of Applied Physics. 2002; 92(2):764-770. http://dx.doi. org/10.1063/1.1483893.

5. Gammer K, Stoiber M, Wagner J, Hutter H, Kullmer R and Mitterer C. Investigations on the effects of plasma-assisted pretreatment for plasma-assited chemical vapour deposition TiN coatings on tool steel. Thin Solid Films. 2004; 461(2):277-281. http://dx.doi.org/10.1016/j.tsf.2004.02.013.

6. Figueroa CA, Ferlauto AS and Alvarez F. Identification of the mechanism limiting nitrogen diffusion in the metallic alloys by in situ photoemission electron spectroscopy. Journal of Applied Physics. 2003; 94(8):5435-5437. http://dx.doi. org/10.1063/1.1605250.

7. Ma S, Li Y and Xu K. The composite of nitride steel of H13 and TiN coatings by plasma duplex treatment and the effect of pre-nitriding. Surface and Coatings Technology. 2001; 137(23):116-121. http://dx.doi.org/10.1016/S0257-8972(00)010732.

8. American Society for Testing and Materials - ASTM. ASM Metals Handbook. West Conshohocken: ASTM International; 1991. v. 4

9. Ochoa EA, Figueroa CA and Alvarez F. The influence of the ion current density on plasma nitriding process. Surface and Coatings Technology. 2005; 200(7):2165-2169. http://dx.doi. org/10.1016/j.surfcoat.2004.09.004. higher than the other treatments. This fact ensures that there was a process of hardening of the material contributing on the wear resistance property.

- The solid nitriding promoted the best results of wear resistance when comparing to the gas and plasma nitriding for the three materials.

- If applying more solid nitriding treatment time we can reduce the amount of material removed during the wear tests.

- The friction coefficient did not suffer big changes with the nitriding processes.

- On the process we called solid nitriding, we could verify the diffusion of both nitrogen and carbon, and this is a characteristic of a nitrocarburizing process, and this process can occur at temperatures near $570^{\circ}$ $\mathrm{C}$, in the ferritic range. Nitrocarburizing also improves the wear resistance; it promotes the formation of a superficial layer with nitrides, carbonitrides of iron, cementite and various carbides.

10. Walkowicz J. On the mechanisms of diode plasma nitriding in N-2-H-2 mixtures under DC- pulsed substrate biasing. Surface and Coatings Technology. 2003; 174-175:1211-1219. http:// dx.doi.org/10.1016/S0257-8972(03)00656-X.

11. Ahangarani SH, Sabour AR, Mahboubi F and Shahrabi T. The influence of active screen plasma nitriding parameters on corrosion behavior of a low-alloy steel. Journal of Alloys and Compounds. 2009; 484(1-2):222-229. http://dx.doi. org/10.1016/j.jallcom.2009.03.161.

12. Castro G, Fernández-Vicente A and Cid J. Influence of the nitriding time in the wear behaviour of an AISI H13 steel during crankshaft forging process. Wear. 2007; 263(7-12):1375-1385. http://dx.doi.org/10.1016/j.wear.2007.02.007.

13. Askari M, Khorsand $\mathrm{H}$ and Seyyed Aghamiri SM. Influence of case hardening on wear resistance of a sintered low alloy steel. Journal of Alloys and Compounds. 2011; 509(24):6800-6805. http://dx.doi.org/10.1016/j.jallcom.2011.03.026.

14. Forati Rad H, Amadeh A and Moradi H. Wear assessment of plasma nitrided AISI H11 steel. Materials \& Design. 2011; 32(5):2635-2643. http://dx.doi.org/10.1016/j. matdes.2011.01.027.

15. Uma Devi M, Chakraborty TK and Mohanty ON. Wear behaviour of plasma nitrided tool steels. Surface and Coatings Technology. 1999; 116-119:212-221. http://dx.doi.org/10.1016/ S0257-8972(99)00118-8.

16. Devaraju A, Elayaperumal A, Alphonsa J, Kailas SV and Venugopal S. Microstructure and dry sliding wear resistance evaluation of plasma nitrided austenitic stainless steel type AISI 316 LN against different sliders. Surface and Coatings Technology. 2012; 207:406-412. http://dx.doi.org/10.1016/j. surfcoat.2012.07.031.

17. Mashreghi AR, Soleimani SMY and Saberifar S. The investigation of wear and corrosion behavior of plasma nitrided DIN 1.2210 cold work tool steel. Materials \& Design. 2013; 46:532-538. http://dx.doi.org/10.1016/j.matdes.2012.10.046.

18. American Society For Testing And Materials - ASTM. G 9995a: standard test method for wear testing with a pin-on-disk apparatus. West Conshohocken; 1995. Reapproved 2000. 